Bioética

\section{Prontuário mÉdico}

Em 10/7/02 o Conselho Federal de Medicina (CFM) editou a Resolução CFM $n^{\circ} 1638$, que "define prontuário médico e torna obrigatória a criação da Comissão de Revisão de Prontuários nas instituições de saúde". Alguns dos artigos mais importantes são:

Art. $3^{\circ}$ - Tornar obrigatória a criação das Comissões de Revisão de Prontuários nos estabelecimentos e /ou instituições de saúde onde se presta assistência médica.

Art. $5^{\circ}$ - Compete à Comissão de Revisão de Prontuários:

l) Observar os itens que deverão constar obrigatoriamente do prontuário confeccionado em qualquer suporte, eletrônico ou papel;

d) Nos prontuários em suporte de papel é obrigatória a legibilidade da letra do profissional que atendeu o paciente, bem como a identificação dos profissionais prestadores do atendimento. São também obrigatórias a assinatura e o respectivo número do CRM;

II) Assegurar a responsabilidade do preenchimento, guarda e manuseio dos prontuários, que cabem ao médico assistente, à chefia da equipe, à chefia da Clínica e à Direção técnica da unidade.

\section{Comentário}

Reforçar a importância do prontuário médico é procedimento óbvio, mas indispensável. A própria experiência dos Conselhos de Medicina comprova que o prontuário é instrumento fundamental não só para contribuir com a qualidade de atendimento ao paciente como também - quando isto se faz necessário - para a defesa do médico em eventuais demandas judiciais e nos Conselhos de Medicina.

\section{Gabriel Oselka}

Referência

Resolução CFM n ${ }^{\circ} 1638$, de 10 de julho de 2002. Diário Oficial União n I53, secção I, 9/8/02, p. 184-5.

\section{Elincea Cinurogica \\ RASTREAMENTO PARA CÂNCER COLORRETAL}

Câncer colorretal é uma das neoplasias malignas mais frequentes no ocidente. É o quinto câncer mais diagnosticado no Brasil, e no sudeste ocupa o segundo lugar. Ele é a quarta causa mais importante de mortes por câncer no País e cerca de metade de doentes morrem em menos de cinco anos após tratamento. A Sociedade Brasileira de Coloproctologia juntamente com Instituto Nacional de Câncer, Colégio Brasileiro dos Cirurgiões e outras sociedades médicas realizaram uma campanha de conscientização da população sobre o câncer do intestino e recomendam programas de rastreamento para câncer colorretal. Indivíduos de baixo risco, a partir de 50 anos, devem realizar anualmente pesquisa de sangue oculto nas fezes e retossigmoidoscopia a cada cinco anos. A partir dos 60 anos, realizar colonoscopia ou enema opaco a cada 10 anos. População de maior risco são: indivíduos maior que 50 anos, história pessoal ou familiar de pólipos e câncer de intestino, retocolite ulcerativa, doença de Crohn, câncer de mama, ovário ou útero. Se pertencer ao grupo de risco, deve iniciar rastreamento aos 40 anos, incluindo colonoscopia. O combate ao câncer colorretal pode ser através de: I) detecção precoce tornando a possibilidade de cura maior 2) diagnóticos e remoção dos pólipos, evitando a progressão da seqüência adenoma-carcinoma que ocorre na maioria dos casos.

\section{Comentário}

Câncer colorretal é a quarta causa de morte em nosso País, estima-se pelo Instituto Nacional do Câncer que ocorram cerca de 1315 óbitos e 3430 casos novos por cem mil homens. 0 número de óbitos supera o câncer do colo uterino na população feminina. 0 aumento progressivo desses casos deve-se a evolução do nosso País rumo ao processo de industrialização, assemelhando as características de países mais desenvolvidos onde 0 câncer colorretal é a segunda ou terceira causa mais importante das neoplasias malignas. Há necessidade crescente de um programa de rastreamento para detecção precoce. É muito oportuno essa iniciativa da nossa Sociedade em realizar a campanha de conscientização da população sobre câncer do intestino.

A efetividade dos diferentes métodos de rastreamento foi analisada por força-tarefa do Serviço Preventivo dos Estados Unidos. 0 teste de pesquisa de sangue oculto nas fezes foi efetivo em reduzir a mortalidade de câncer colorretal de 14,5 para 9,I mortes por mil habitantes'. Os recentes estudos não evidenciaram a redução de mortalidade com a sigmoidoscopia flexível isoladamente como método de rastreamento, porém um estudo anterior com a retosigmoidoscopia rígida demostrou uma redução de mortes causadas por câncer do cólon e reto dentro do alcance do aparelho ${ }^{2}$. A combinação entre sigmoidoscopia rígida e pesquisa de sangue oculto nas fezes demostra ser mais efetiva que sigmoidoscopia rígida isoladamente ${ }^{3}$.

A colonoscopia também reduziu a mortalidade por câncer colorretal', porém acompanhados de maior custo e número de complicações. Métodos utilizando biologia molecular ainda estão para ser definidos. Os indivíduos de maior risco necessitam de programas específicos.

Infelizmente não existem estudos recentes em nosso meio quanto aos diferentes exames de rastreamento. A efetividade desses métodos como a pesquisa de sangue oculto combinados ou não com a retosigmoidoscopia ainda precisa ser avaliada em nosso meio.

\section{Fang Chia Bin}

\section{Referências}

I. Pignone M, RichM, TeutschS, BergAO, Lohr KN. Screening for colorectal cancer in adults at average risk: a summary of the evidence for the U.S. PreventiveServices Task Force. Ann Intern Med 2002; I37:132-4I.

2. SelbyJV, Friedman GD, Quesenberry CPJr, Weiss NS. A case-control study of screening sigmoidoscopy and mortality from colorectal cancer. N Engl J Med 1992; 326:653-7.

3. Winawer S], Flehinger B], Schottenfeld D, Miller DG. Screening for colorectal cancer with fecal occult blood testing and sigmoidoscopy. J Natl Cancer Inst 1993; 85: I 3 I -8. 4. Müller $A D$, Sonnenberg $A$. Protection by endoscopy against death from colorectal cancer. A case-control study among veterans. Arch Intern Med 1995; 155: 174I-8. 